metric deflections. The emotive response in its unmistakable form as a sharp movement occurring about two seconds after its exciting cause is always in one direction, i.e. in the direction of decreased resistance -increased permeability, poro-dilatation or, if you prefer to think it so, contraction of living matter round pores so as to dilate them. And in many thousands of observations $I$ have never witnessed any similar movement in the opposite direction-i.e. in the direction of increased resistance. All that is ever seen in that direction is the gradual remission of a previous deflection in the emotive or excitatory direction. If you regard the question in its psychological aspect, you will soon be satisfied that the matter could not be expected to come out otherwise. Our pleasures and pains are not simple opposites producing opposite physiological effects. Pains are active and exciting states in our conscious life, sharply contrasting with their background. Pleasure is more often merely the subsidence and relief from pain, a gradual recovery of the untroubled state. A pin-prick suddenly excites emotion, and the emotion gradually falls to rest. . There is no counterpart pleasure equal and opposite to a pin-prick. Pleasure is of necessity gradual. Too sudden pleasure-joy, as we call itis exciting, and causes discharge down the nerves that acts precisely like painful excitements and gives rise to electrical effects in the same emotive direction.

I4. We distinguished a few moments ago between imaginatives and positives according as threatened pains produced larger or smaller effects than real pains. It is convenient to draw another kind of distinction according to the extent of body-surface over which the response is manifested. The response to "weak" stimuli in the great majority of men and women is exclusively palmar (and plantar). But with "strong" stinuli, and in certain cases with "weak" stimuli as well, the response can also be manifested by the forearm (and by the leg) as well as by the hand (and foot). Such cases may be designated as "sensitives" to distinguish them from the others who are relatively insensitive, but since these others are in a majority, and it would seem inappropriate to designate the majority of mankind as insensitive, it is better to call them "normals." These two labels, "sensitives" and "normals," are not intended to imply any division into two hard-and-fast categories, but rather a scale of differences grading between two extremes. Indeed, I have satisfied myself in at least one case that a subject classified at a first sitting as "normal" was temporarily raised to the degree of "sensitive" in consequence of a rather violent fit of "temper.",

It is convenient to reserve the designation "insensitive" for cases low down in the normal scale, giving in response to ordinary stimuli little or no palmar reaction-i.e. a doubtful response of the order of I per 100 of the initial resistance.

I5. Provisionally, then, our observations can be systematised in accordance with the following scheme :

\begin{tabular}{|c|c|c|c|}
\hline \multirow{2}{*}{ Class. } & \multicolumn{2}{|c|}{ Emotive Response. } & \multirow{2}{*}{ Examples. } \\
\hline & Hand. & Forearm. & \\
\hline $\begin{array}{l}\text { I. Sensitives } \ldots \\
\text { (“Imaginatives") }\end{array}$ & Yes & Yes & $\begin{array}{l}\text { Spiritualistic mediums } \\
\text { and others. }\end{array}$ \\
\hline II. Normals $\quad \ldots$ & Yes & No & $\begin{array}{l}\text { The majority of men } \\
\text { and women. }\end{array}$ \\
\hline $\begin{array}{l}\text { III. Insensitives } \ldots \\
\text { (" Positives") }\end{array}$ & No & No & $\begin{array}{l}\text { Pythiatics. "Shell } \\
\text { shock" cases. }\end{array}$ \\
\hline IV. Others $\ldots$. & - & - & $\begin{array}{l}\text { "Shell shock" cases } \\
\text { and others. }\end{array}$ \\
\hline
\end{tabular}

Class I._-"Sensitives" giving large responses (10 per cent. or more of the original resistance) from the forearm and from the hand.

Class II._-"Normals" giving moderately large response ( 2 to 5 per cent.) from the hand, but little or no response from the forearm.

Class III._- "Insensitives" giving little or no response ( 1 per cent.) from the hand, and, of course also the forearm.

Class IV.-(a) Subjects who, by reason of their state of health, were obviously unfit to undergo examination, and $(b)$ subjects who declared themselves as unable to stand it.

Subjects of Class I. and Class II. include those who were characterised a moment ago as "imagina. tives." The three spiritualistic mediums to whom I referred just now were included in Class $I$. Class III. comprises people of duller imagination, or perhaps of firmer fibre, whom we called "positives."

At this early stage indeed, when the number of properly observed cases is so small and the danger of imperfect observation so great, it seems to me hazardous even to talk about rules and exceptions or to attempt a classification. Nevertheless, if the attempt is made without prejudice, and if the results of observation are recorded in physical units by the side of what in medical parlance is the clinical history of the subject, a preliminary classification is not only permissible, but also necessary.

Let me again refer to the present attempt and make good the point that we may expect to find the unexpected, that so-called regular results may be exceptional and vice versa.

16. Pythiatics.-Hysterical subjects or, as they are now called, "pythiatics," men as well as women, seem to be exceedingly sensitive and make a great fuss; but when they have been persuaded to sit still in an armchair and connected up with the galvanometer and tested by ordinary stimuli-pin-prick, false and real; match-burn, false and real-lo and behold! they exhibit little or no response. They belong to Class III., that of the "insensitives"; and we are reminded of the fact that in exaggerated-i.e. patho logical-degree the hysterical or pythiatic state is found to include anæsthesia, loss of sensibility, as a leading symptom. But, of course, more observations are necessary, and more observers.

\title{
The Modern Londoner and Long Barrow Man.
}

$\Delta \mathrm{T}$ a meeting of the Royal Anthropological Institute held on March 8, Prof. F. G. Parsons read a paper on "The Modern Londoner and Long Barrow Man," in which he discussed a claim made by Dr. Macdonell and Prof. Karl Pearson that the head shape of Londoners of the seventeenth and eighteenth centuries was more like that of the Long Barrow men than of any other race. Prof. Parsons, however, showed, by a detailed comparison of contours obtained NO. 2684 , VOL. IO7] from thirty male London skulls of the seventeenth and eighteenth centuries dug up in the Clare Market district, and corresponding with the averages obtained by Dr. Macdonell from his London skulls found at Whitechapel and Moorfields, with those of twenty Long Barrow skulls from Yorkshire, Wiltshire, and Gloucestershire, that in the head measurements, in the depth of the orbital openings, in the length of the face, and in other anatomical details the London 
skulls differed markedly from those of the Long Barrow men. On the other hand, in every respect these London skulls corresponded more closely with those of Anglo-Saxons than with those of Long Barrow men. Occasionally a Londoner might reproduce the Long Barrow type, as in the case of the notorious thief Jonathan Wild, but these cases were so rare as not to affect the average contour.

Further, the Londoner of to-day had changed his head shape from that of the seventeenth-century Londoner, but it was in the direction of the shortheaded mid-European race, and farther away still from the Mediterranean type, of which the Long Barrow men were such good examples.

When the average contours of the modern London skulls were superimposed upon those of the Long Barrow men, it was at once evident that there were two sets of differences, which Prof. Parsons provisionally described as "masticatory" and "respiratory." The former consisted of increased length of skull in front of the auditory meatus, of a tilting forward of the malar bone and outer margin of the orbit, of a greater splay of the zygomatic arch, of an increased width of the ramus of the jaw, and of a flattening of the side of the head. All these changes were just as evident in an average contour of Eskimo skulls as in that of Long Barrow men, and they were all explicable by assuming an increased development of the great masticatory muscles.

The second set of changes between the Long Barrow and London skulls was the deep face and deep orbital openings of the latter, as in all Nordic skulls. The face of the English child at birth closely agrees with that of the Long Barrow man, and at three and five months the orbits and nose have markedly increased in depth from above downward. This is to be attributed to the narrowing and deepening of the nose to adapt the individual to a cold climate, ensuring that the air shall be more perfectly warmed by contact with the turbinated bones which act as radiators. As the nasion moves up the tops of the orbits have to keep pace with it, and so the characteristic depth of the Nordic orbits is accounted for.

It is interesting to note that though the Eskimo agree with the Long Barrow folk in the first set of masticatory characteristics, they differ from them and agree with the Nordic people in the second set of respiratory changes.

\section{Pendulum Operations in India and Burma. ${ }^{1}$}

THE paper referred to below, recently published by the Survey of India, is an opportune contribution to geodetic knowledge. It gives the results of pendulum observations at 108 stations distributed over mountains, plateaux, plains, and coasts. Col. (now Sir) G. P. Lenox Conyngham, Major Cowie, and Capt. Couchman were the observers. The work extended over six years, I908-r 3 , and it is evident that unremitting care was bestowed upon it throughout.

This is the first attempt made outside the United States of America to apply to pendulum observations the correction for isostasy, first introduced by $\mathrm{Mr}$. Hayford in Igog when he was reducing the pendulum observations of America. The deduction of the correction for isostasy for any particular pendulum station involves considerable labour; the whole earth has to be divided into circular concentric zones, with the station as their centre; the mean heights of the several zones, above or below sea-level, have then to be determined from maps. This course has to be pursued de novo for each successive station. The

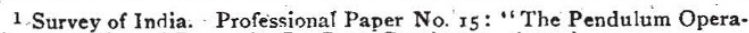
tions in India and Burma." By Capt. Couchman. (xgt5.)

No. 2684 , VOL. IO7] application of Hayford's system to the pendulum stations of India is thus a most interesting feature of Capt. Couchman's work, and students of modern geodesy will find his explanations helpful and clear. The final results obtained by Couchman furnish strong evidence in support of Hayford's contention that isostatic compensation is complete at a depth of about II $3 \mathrm{~km}$.

Geodesy is a science demanding world-wide cooperation; the results obtained in one continent require to be tested in others. The theory of isostasy initiated in America has now been shown by Capt. Couchman to explain anomalies in Asia. But this is not sufficient; geodetic results and theories should be submitted to an international association for scrutiny. The old International Geodetic Association, which had been endeavouring for fifty years to coordinate the surveys of all countries, came to an end in 1914, when the war broke out. If geodesy is to progress, a new international association will have to be formed.

The old association, always sympathetic and anxious to help, had an uphill task; it had to contend with jealousies, and to accept results, whether good or bad, without being able to discriminate or criticise. Its authority rested largely on the personal reputation of the late Prof. Helmert, whose right to the position of director was universally recognised, and whose death during the war was lamented in many countries.

In I9I4, when the old association came to an end, two questions were awaiting an international decision, namely, the introduction of a new spheroid of reference and the treatment of isostasy. Obsolete spheroids of reference are still employed by various surveys, and their continuance is due, not to any local belief in their correctness, but to an unwillingness to face the laborious complications of a change until a new spheroid has received international approval.

The problem of isostasy is also awaiting international consideration. In America Hayford and Bowie have worked out a complete system of computations, and in India Crosthwait and Couchman have followed Hayford's lead. ${ }^{2}$ Will the system be accepted in Europe? When this question comes to be considered by the future international association Capt. Couchman's work on the pendulum operations in India will be found a useful and weighty contribution.

\section{University and Educational Intelligence.}

Notice is given by the University of London that applications for grants from the Dixon Fund for assisting scientific investigations must be made to the Academic Registrar of the University, South Kensington, S.W.7, before May I5 next.

Two further lectures under the scheme for the exchange of lecturers between Holland and England are announced. Both will be given at the rooms of the Royal Society of Medicine, I Wimpole Street; the first, by Prof. W. Einthoven, of Leyden, entitled "The Relation of Mechanical and Electrical Phenomena of Muscular Contraction, with Special Reference to the Cardiac Muscle," will be delivered on May 2 at 5 p.m.; and the second, by Prof. Bolk, of Amsterdam, entitled "The Somatic Changes in Affections of the Endocrine Glands and their Significance in the Evolution of Man." on May i2 at 5 p.m. The lectures, which will be delivered in 2 In Professignal Paper No. I3 (rgr2) Crusthwait applied Hayford's method to the observations of the plumb-line in India. 